\title{
NATAL SOLIDÁRIO NA ORGANIZAÇÃO NÃO GOVERNAMENTAL: I EVENTO VIRTUAL PARA CRIANÇAS
}

\author{
Gabriele Santos Pereira, Jaqueline Costa Castilho Moreira \\ Universidade Estadual Paulista - UNESP, Curso de Educação Física, Departamento de Educação Física, \\ Campus de Presidente Prudente, SP. E-mail: gabbygabrielesantos@gmail.com
}

\begin{abstract}
RESUMO
Este artigo intenciona mostrar tanto como uma atividade pontual de coparticipação entre instituições permite compartilhar estratégias de uso, adaptação e/ou combinação dos jogos virtuais com o potencial tecnológico disponível nesses locais; como também este mesmo evento pode favorecer um melhor entrosamento entre a universidade e o terceiro setor. Considerando que não existe uma ciência específica que faça referência a metodologia de organização de eventos, esta foi adaptada de Poit $^{(2)}$. O estudo possibilitou investigar algumas potencialidades e fragilidades, que também são recorrentes em outros eventos de pequeno porte. Dentre os aspectos positivos foi ressaltada a importância da aproximação teoria e prática "pedagógica" possibilitada pela parceria entre as instituições.
\end{abstract}

Palavras-chave: educação física, coparticipação, exergames, extensão, evento recreacional.

\section{SOLIDARITY IN CHRISTMAS NON-GOVERNMENTAL ORGANIZATION: I VIRTUAL FOR KIDS EVENT}

\begin{abstract}
This article intends to show as much as a specific activity of co-participation between institutions allows sharing use of strategies, adaptation and / or combination of virtual games with the technological potential available in these locations: as well as this same event can foster a better understanding between the university and the third sector. Whereas there is no specific science that refers to events organization methodology, this was adapted from Poit ${ }^{(2)}$. The study made it possible to investigate some strengths and weaknesses, which are also applicants in other small events. Among the positive aspects it was highlighted importance of the approximation theory and practice "teaching" made possible by the partnership between the institutions.
\end{abstract}

Keywords: physical education, co-participation, exergames, extension, recreational event. 


\section{INTRODUÇÃO}

A inserção da temática virtualidade em ambientes de ensino da Educação Básica vem sendo bastante discutida internacionalmente e também no Brasil. Tem-se colocado em pauta vários aspectos: a disponibilização de tecnologia (máquina fotográfica, filmadora, celular, internet, entre outros) aos envolvidos com o processo de aprendizagem para registro e discussão; o questionamento de como o contexto virtual pode colaborar com a superação entre as lacunas teoria e prática; o descompasso entre a infraestrutura educacional e o currículo oficial; e ainda a situação reversa, ou seja, as limitações de inserção ao mundo digital por questões econômicas, políticas, sociais, culturais e cognitivas.

No cotidiano brasileiro é recorrente associar os jogos virtuais a tecnologias de ponta, altos custos financeiros e consequente restrição de acesso a uma grande camada da população. Entretanto, acompanha-se o entendimento de Levy ${ }^{(1)}$ sobre o conceito de virtual, como um processo de transformação de uma forma de ser em outra, uma simulação, uma representação.

Incorpora-se ainda aos jogos virtuais, a ideia de que eles podem ser recursos pedagógicos aplicados e/ou adaptados em combinação com outras tecnologias disponíveis e de baixo custo. Situação que torna possível implementar este tipo de jogo nos mais variados ambientes educacionais, formais, não formais e informais.

Este artigo intenciona mostrar como uma atividade pontual de coparticipação entre instituições permite que sejam compartilhadas estratégias de uso, adaptação e/ou combinação dos jogos virtuais com o potencial tecnológico disponível nesses locais, como também esse mesmo evento pode favorecer um melhor entrosamento entre a universidade e o terceiro setor.

Nesta perspectiva foram destacadas neste trabalho, algumas atividades lúdicas de simulacro $^{(1)}$ e de representação ${ }^{(1)}$ como o "cineminha" e a dança com utilização dos equipamentos da instituição como a televisão associada a internet; e o uso de exergames, jogos virtuais que necessitam de grande movimentação do corpo para funcionar e de uma plataforma interativa capaz de captar esses movimentos por meio de sensores.

Em síntese, o objetivo deste trabalho é integrar e disseminar o conhecimento desenvolvido na Universidade sobre a temática da virtualidade em ambientes educacionais não formais, como as organizações não governamentais (Ong)s, por meio de um evento.

\section{METODOLOGIA}

Acompanhando o objetivo exposto e considerando que não existe uma ciência específica que faça referência a metodologia de organização de eventos, foi adaptada de Poit ${ }^{(2)}$ uma estrutura organizativa para o fenômeno, na qual foram destacadas cinco fases: ideia/concepção, projeto, planejamento/pré-evento, execução do evento, pós-evento.

$\mathrm{Na}$ fase ideia/concepção, por sugestão deste mesmo autor, retomou-se sucintamente a memória deste estudo. Iniciado em 2014 como uma ação voluntária intitulada "A coparticipação dos exergames em eventos escolares" e realizada por meio de uma parceria entre discentes e uma docente do curso de Educação Física da UNESP e de uma entidade do terceiro setor; essa ação pontual foi abarcada como um dos objetivos operacionais do Projeto "Exergames na Educação Inclusiva", enviado ao "Comitê de Ética/Plataforma Brasil", cadastrado e aprovado sob n CAAE 41735715.0.0000.5402 no ano seguinte.

O projeto foi concebido com a intenção de oferecer momentos de inserção ao mundo virtual aos jovens institucionalizados, por meio de jogos tecnológicos e atividades lúdicas que envolvem o simulacro $^{(1)}$ e a representação ${ }^{(1)}$, em local em que o acesso a este tipo de vivência, muitas vezes é restrita.

Para Poit ${ }^{(2)}$, a segunda fase de um evento é aquela que torna o projeto em um instrumento de transformação, de ideia para ação. Assim o evento foi denominado como o "I Evento Virtual para Crianças" ou "I Virtual 4 Kids Event" e destinado a atender crianças e jovens com algum tipo 
de limitação de acesso ao mundo virtual. Foi escolhida uma Ong $^{(3)}$ de Presidente Prudente/SP, fundada em 1969 e localizada no bairro comercial/residencial Jardim Estoril. A instituição foi escolhida por ser um contexto de educação não formal, estabelecido na cidade há 46 anos, que tem como finalidades: assistência e proteção social, apoio a aprendizagem e permanência escolar, oferecimento de atividades educacionais complementares. Como exemplo dessa última finalidade tem-se o projeto de incentivo a leitura "Caminhos do Saber" ${ }^{(4)}$. A organização atende diariamente 70 jovens em contexto de vulnerabilidade, em contra turno, com faixa etária variando entre 6 a 14 anos, provenientes do Jardim Estoril e de bairros de seu entorno. Após a visita e convite de coparticipação, em acordo com a Ong foi estabelecido o período do dia 7 a 11 de dezembro para realização do evento.

$\mathrm{Na}$ fase de planejamento ou pré-evento foram feitas reuniões com objetivo de antecipar possíveis situações e como resolvê-las. Uma das decisões resultantes destes encontros foi quanto aos caminhos a serem percorridos para dar visibilidade ao evento. Além da divulgação direta ("boca a boca") nas salas de aula da Educação Física, no período da manhã e à noite e cartazes nos corredores e cantina, foi disponibilizada uma página do evento no facebook ${ }^{(5)}$. Foram decididas as atividades que melhor se encaixavam ao tema Natal e ao assunto da virtualização do corpo e dos jogos virtuais ${ }^{(1)}$ (6); a programação bem como os materiais e equipamentos para sua execução, o número de graduandos necessários para a realização da programação e sobre a premiação que deveria incluir todas as crianças, em termos de quantidades e valores, bem como quanto à forma de arrecadação. A partir desse delineamento foram pesquisadas quais empresas locais poderiam ser abordadas para solicitação de apoio/ colaboração/patrocínio e/ou doação para a premiação e a busca e seleção de graduandos voluntários. Em relação às empresas, entrou-se em contato por telefone com cada uma delas e aquelas que mostraram interesse foram visitadas pessoalmente para entrega de um ofício explicando o objetivo do projeto em questão, sua vinculação com a universidade, a programação do evento e por fim requisitando apoio, colaboração/patrocínio e/ou doação. Apenas uma empresa local mostrou-se interessada, alegando achar "importante o apoio aos projetos sociais da região". Foi feita nova visita a esta empresa, e em reunião com a representante de marketing foi apresentado o projeto original cadastrado no PROEX EVENTOS. Após o término da reunião, a pessoa responsável ficou de entrar em contato sobre a decisão em relação à forma de contribuição da empresa com o evento cultural. A empresa optou pela doação de brindes com sua marca institucional. Assim foram doadas camisetas, potes de pipoca, bonés e mini refrigerantes, dimensionados para atender 80 crianças. Com a doação, os envolvidos com o evento reorganizaram os brindes, tornando possível entregar um kit para cada criança. A seleção de graduandos voluntários para trabalhar nos dias do evento foi feita a partir do preenchimento de formulário eletrônico disponibilizado no site do evento. Em contrapartida a participação, ficou acordada com esses voluntários que eles receberiam um certificado de horas. No formulário constavam informações como nome, RG, CPF, RA, curso e etc. Foram inscritos treze graduandos, porém somente nove voluntários compareceram no evento. Essa redução de treze para nove não interferiu no funcionamento da programação. Os graduandos foram divididos em equipes, nas quais cada um tinha sua função: criação da atividade, preparação dos materiais necessários, escolha de quem seria o monitor e dos auxiliares e estabelecimento de um "plano b", caso a atividade por algum motivo não pudesse ser realizada. Essa organização colaborou para que ocorresse uma melhor dinâmica durante a efetivação do programa do evento. 


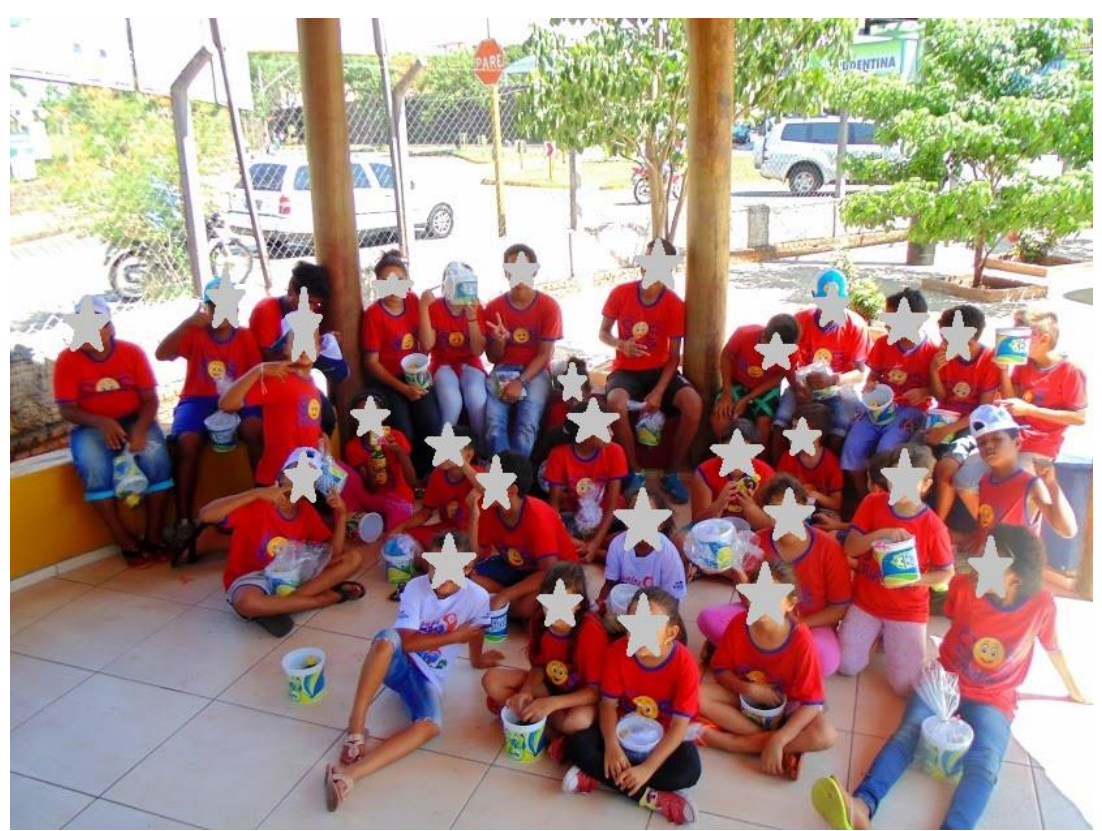

Figura 01. Encerramento do I Evento Virtual para Crianças Institucionalizadas. Fonte: autoria própria.

Em relação à fase quatro, que Poit ${ }^{(2)}$ denomina como execução, neste artigo ela aparece como um breve relato dos acontecimentos. No primeiro dia do evento contou-se com a equipe responsável pelas atividades de dança. A descrição a seguir foi extraída de um dos relatórios de um dos monitores:

"Estava uma tarde ensolarada e as crianças e adolescentes foram levados para a área externa da instituição, onde existe um quiosque. Neste local, a equipe se apresentou, foram explicados os objetivos do evento e deu-se início às atividades planejadas para o dia. Foram colocadas músicas relacionadas aos games e os jovens foram convidados a participar dançando. Percebeu-se que algumas crianças tiveram dificuldade em participar da dança. Algumas se recusaram logo de início, mas ao final, todos estavam participando. Percebeu-se que algumas poucas crianças já conheciam algumas das coreografias realizadas pelos monitores, porque já tinham tido contato com o game selecionado para utilização neste dia do evento; mas como a maioria ainda não tinha tido contato com o console em questão (XBOX KINECT), estas tiveram dificuldade em reproduzir a coreografia apresentada pelos monitores. Realizada a atividade de dança prevista, seguiu-se com o jogo virtual JUST DANCE 2014. Os jovens foram dividimos em quartetos, o jogo foi apresentado e a partir daí os participantes vivenciaram o exergame de dança. Percebeu-se uma satisfação positiva por parte das crianças; elas se sentiram muito à vontade com o jogo dizendo que aquilo era legal. Todos participaram no mínimo duas vezes cada."(Monitor 3).

No segundo dia do evento foi realizada uma recreação com atividades lúdicas, como circuito, brincadeiras com bola e depois foi realizado um jogo de representação, que tinha como premiação a distribuição dos brindes doados pela empresa local já mencionada. Ao final, todas as crianças receberam um kit, mesmo aquelas que não haviam ganhado em nenhuma rodada. 0 "cineminha" foi organizado como atividade do terceiro dia em uma sala da instituição. Foram utilizados papel pardo para tirar a claridade do local, data show, caixa de som, colchonetes e 
almofadas espalhados pelo ambiente e distribuídos mini refrigerantes e pipoca, para que o ambiente ficasse o mais confortável possível. O filme selecionado foi o "Pixels", por seu enredo aproximar-se com a temática tratada no evento. No encerramento da sessão foi feita uma "roda de discussão" sobre o que as crianças entenderam do filme e uma "provocação" sobre o que os games antigos haviam despertado nelas. O último dia foi reservado aos exergames com o XBOX Kinect disponibilizado em rodízio de turmas. Nesse momento final foi feita uma avaliação pelos participantes do projeto na sala de artes da instituição. Os jovens foram solicitados a desenhar a atividade que mais gostaram durante a realização do evento.

A última fase refere-se ao pós-evento descrito por Poit ${ }^{(2)}$ como desmontagem dos equipamentos e sua devolução, os agradecimentos aos parceiros/apoiadores/colaboradores, a quitação dos débitos assim como uma avaliação de toda a execução do evento, na perspectiva tanto dos envolvidos como monitores, voluntários, e etc. como dos participantes, pessoas para quem o evento foi destinado. O desenho confeccionado no último dia pelos participantes do projeto possibilitou uma avaliação direta. Mesmo com a variação de faixa etária desses jovens houve um consenso positivo na apreciação das vivências expressas pelos desenhos entregues. Importante ressaltar que neste dia havia na Ong apenas 36 jovens. Deste total, vinte apontaram que os exergames foram a atividade que mais gostaram; seguida do "cineminha", no qual nove demonstraram ter gostado do filme "Pixels", quatro apontaram o "jogo de representação" como a atividade que mais agradou e com três votos a recreação. Não houve nenhum desenho indicando que algum participante desgostou do evento. Foi realizada outra avaliação com os graduandos. No balanço de potencialidades e fragilidades apontado por eles, surgiram vários elementos que ajudaram na confecção deste escrito. Dentre eles: a dificuldade de se coletar apoio em momentos festivos como as vésperas do Natal; a importância do evento como uma possibilidade de transposição teoria e prática, aprofundada no item conclusão, como considerações em relação ao projeto. Quanto à empresa que colaborou doando brindes institucionais, foi realizado novo encontro no qual houve a entrega de uma apresentação digital com os objetivos do evento, a programação e algumas imagens das vivências tomando o cuidado de não expor os jovens que participaram, a representante do marketing. Quanto à Ong, os responsáveis agradeceram o empenho dos graduandos e convidaram novamente para desenvolver novos projetos em coparticipação.

\section{RESULTADOS}

Embora o balanço em relação ao evento possa ser considerado positivo acompanhamos a sugestão de Pais $^{(7)}$ que discute os resultados apresentando-os em: planejamento, realização e avaliação.

No item planejamento destacou-se o recrutamento, uma tarefa que envolveu elaboração de um formulário virtual para inscrição, divulgação, atestado com horas expedido pela coordenadora do departamento de Educação Física e pela professora responsável pelo projeto, e a questão da desistência, que é uma dificuldade apontada por outros autores ${ }^{(7)}$. Segundo Pais ${ }^{(7)}$, esse fenômeno acontece porque pequenos eventos como este, não são tão aliciantes e nem provocam recompensas sociais, como o prestígio em fazer parte de um evento de maior envergadura. Ainda neste item, relevante ressaltar a baixa adesão de apoio/colaboração/patrocínio e/ou doação para a premiação e também para viabilizar a compra de materiais como canetinhas, papel sulfite entre outros, embora tenha sido feito grande esforço para entrar em contato com estas empresas. Esse problema também foi levantado em Pais ${ }^{(7)}$.

Quanto ao item realização, este evento assemelha-se aos eventos esportivos que se desenvolvem por duas vertentes: especificações técnicas e valor simbólico. Ambas também referenciadas em Pais ${ }^{(7)}$. A questão técnica refere-se ao regulamento do evento, com as regras e normas de cada jogo e também as normas de conduta em cada atividade, em especial durante o 
“cineminha". Em relação ao valor simbólico, uma alegria semelhante a relatada por Pais ${ }^{(7)}$ também foi observada pelos monitores e voluntários, principalmente porque o evento foi realizado em período natalino, momento que as crianças tem a expectativa de serem presenteadas.

Referindo-se à avaliação tanto das crianças e jovens atendidos pela Ong, como daquela realizada pelos monitores e voluntários o balanço foi positivo. Resultado este propiciado pelos desenhos mencionados e pelos relatos, respectivamente. Outro aspecto a salientar é a disponibilização da Ong em acolher novos projetos semelhantes a este.

\section{CONCLUSÃO}

Um aspecto que deve ser aprimorado em próximas edições relaciona-se a busca por apoio/colaboração/patrocínio e/ou doação. Essa coleta deve ser realizada ao longo do ano e não somente no mês anterior ao evento. A escolha do período natalino para a execução do evento também precisa de reflexão por dois motivos: o primeiro por dificultar a colaboração das empresas. Nesta época do ano existe uma concorrência de ações de voluntariado e a disputa por doação é acirrada. O outro fator que sugere discussão é que com o término do ano letivo das escolas, nas primeiras semanas de dezembro o público da instituição torna-se inconstante, reduzindo o número de atendimentos diários em contra turno.

E por último, mas não menos relevante, a parceria entre as instituições foi um aspecto positivo que reforçou no decorrer do evento, a importância da aproximação teoria e prática "pedagógica" e que merece ser mantida. Por meio dela, os graduandos experimentaram os desafios a serem transpostos ao entrar em contato com a realidade dos jovens institucionalizados; o que contribui efetivamente para diminuir as distâncias existentes entre o conhecimento disseminado no ensino superior e as práticas no ensino não formal.

\section{REFERÊNCIAS}

Lévy P. O que é virtual. In: Neves P, tradutor. O que é o virtual? São Paulo: Editora 34; 1996.

Poit DR. Organização de Eventos Esportivos. 3 ed. São Paulo: Phorte; 2004.

Rede Criança ReCriaPrudente [Internet]. Presidente Prudente; s.d. [citado 2016 ago.16]. Disponível em: http://www.recriaprudente.org.br/site/entidades/default. asp?cod=8.

PROJETO CAMINHOS DO SABER. ReCriaPrudente [Internet]. Presidente Prudente; s.d. [citado 2016 ago.16]. Disponível em:

http://www.recriaprudente.org.br/site/entidades/getPDF.asp?ent=8\&proj=1163

@VirtualKids [Internet]. Presidente Prudente; 2015. [citado 2016 ago.16]. Disponível em: https://www.facebook.com/Virtual4KidsEvents/?ref=page_internal/.

Feres Neto, A. Videogame e educação física/ciências do esporte: uma abordagem à luz das teorias do virtual. http://www.efdeportes.com/ Revista Digital [Internet]. 2001 [citado 2016 ago.16];10(88):1-9. Disponível em: http://www.efdeportes.com/efd88/video.htm.

Pais S.A.M. Planeamento, realização e avaliação de um evento desportivo para deficientes intelectuais [Dissertação ]. Porto: Faculdade de Desporto da Universidade do Porto; 2009. Disponível em: https://sigarra.up.pt/flup/pt/pub_geral.show_file?pi_gdoc_id=1409 